\title{
Digital Health Strategies for Cervical Cancer Control in Low- and Middle-Income Countries: Systematic Review of Current Implementations and Gaps in Research
}

Andrea H Rossman ${ }^{1}$, BSE; Hadley W Reid ${ }^{2}$, BA; Michelle M Pieters ${ }^{3}$, MSc; Cecelia Mizelle ${ }^{3}$, BSc; Megan von Isenburg $^{4}$, MSLS; Nimmi Ramanujam ${ }^{1,3}, \mathrm{PhD}$; Megan J Huchko, ${ }^{3,5}$ MPH, MD; Lavanya Vasudevan ${ }^{3,6}, \mathrm{MPH}, \mathrm{PhD}$, $\mathrm{CPH}$

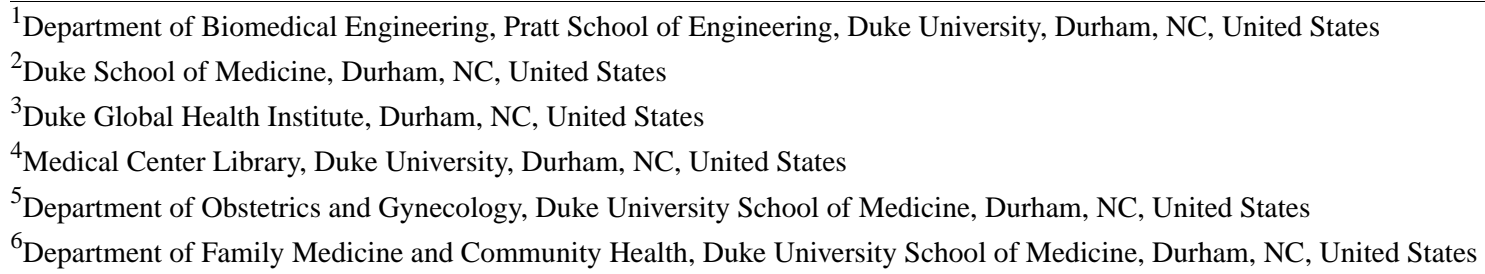

\section{Corresponding Author:}

Lavanya Vasudevan, MPH, PhD, CPH

Department of Family Medicine and Community Health

Duke University School of Medicine

2200 W. Main Street

Suite 600

Durham, NC, 27705

United States

Phone: 19196131423

Email: lavanya.vasudevan@duke.edu

\section{Abstract}

Background: Nearly $90 \%$ of deaths due to cervical cancer occur in low- and middle-income countries (LMICs). In recent years, many digital health strategies have been implemented in LMICs to ameliorate patient-, provider-, and health system-level challenges in cervical cancer control. However, there are limited efforts to systematically review the effectiveness and current landscape of digital health strategies for cervical cancer control in LMICs.

Objective: We aim to conduct a systematic review of digital health strategies for cervical cancer control in LMICs to assess their effectiveness, describe the range of strategies used, and summarize challenges in their implementation.

Methods: A systematic search was conducted to identify publications describing digital health strategies for cervical cancer control in LMICs from 5 academic databases and Google Scholar. The review excluded digital strategies associated with improving vaccination coverage against human papillomavirus. Titles and abstracts were screened, and full texts were reviewed for eligibility. A structured data extraction template was used to summarize the information from the included studies. The risk of bias and data reporting guidelines for mobile health were assessed for each study. A meta-analysis of effectiveness was planned along with a narrative review of digital health strategies, implementation challenges, and opportunities for future research.

Results: In the 27 included studies, interventions for cervical cancer control focused on secondary prevention (ie, screening and treatment of precancerous lesions) and digital health strategies to facilitate patient education, digital cervicography, health worker training, and data quality. Most of the included studies were conducted in sub-Saharan Africa, with fewer studies in other LMIC settings in Asia or South America. A low risk of bias was found in 2 studies, and a moderate risk of bias was found in 4 studies, while the remaining 21 studies had a high risk of bias. A meta-analysis of effectiveness was not conducted because of insufficient studies with robust study designs and matched outcomes or interventions.

Conclusions: Current evidence on the effectiveness of digital health strategies for cervical cancer control is limited and, in most cases, is associated with a high risk of bias. Further studies are recommended to expand the investigation of digital health strategies for cervical cancer using robust study designs, explore other LMIC settings with a high burden of cervical cancer (eg, South America), and test a greater diversity of digital strategies. 
(J Med Internet Res 2021;23(5):e23350) doi: 10.2196/23350

\section{KEYWORDS}

cervical cancer; digital health; mobile phones; low- and middle-income countries; colposcopy; uterine cervical neoplasms; telemedicine or mobile apps; cell phones; developing countries

\section{Introduction}

\section{Background}

Annually, 311,000 women die from cervical cancer worldwide, with $90 \%$ of the deaths occurring in low- and middle-income countries (LMICs). [1]. To reduce this high burden of mortality, it is critical to implement and scale sustainable and effective cervical cancer control programs in LMICs. However, cervical cancer control programs in LMICs must overcome individual-, provider-, and health system-level bottlenecks to health service delivery, access, and utilization [2-5]. In the last decade, health systems in LMICs have taken advantage of the increasing prevalence of digital technologies, particularly mobile phones, to circumvent some of the bottlenecks in cervical cancer control. However, systematic reviews of the effectiveness of such digital health strategies in LMIC settings are lacking, especially regarding how such strategies may improve the delivery, access, and utilization of cervical cancer control programs [4].

Primary prevention strategies for cervical cancer control focus on vaccination against human papillomavirus (HPV), whereas secondary prevention strategies focus on early screening and treatment of precancerous lesions [6,7]. Where implementation of preventive services is inadequate, cervical cancers are typically detected at advanced stages, further contributing to high mortality rates $[8,9]$. Commonly used screening methods include visual inspection with acetic acid (VIA), visual inspection with Lugol iodine, and HPV DNA testing [10,11]. Although an initial cervical cancer screening is possible at primary health facilities, or even at the community level by frontline health workers, follow-up procedures, diagnosis, and treatment require access to trained medical providers (eg, expert colposcopists). The treatment of invasive cancer also requires secondary or tertiary health facilities with specialized equipment for surgery, chemotherapy, and radiation [11]. The management of invasive cancer includes long-term retention of women in care, with regular follow-ups and palliative care as applicable. To be effective, cervical cancer control programs must not only achieve high rates of screening coverage among eligible women but also ensure that women who screen positive receive timely treatment and support for long-term management [12]. There is a lack of systematic reviews to understand how digital health strategies affect cervical cancer control in LMICs across the continuum spanning from prevention to palliative care.

There is growing interest from local, national, and global stakeholders in integrating digital health strategies with cervical cancer control programs in LMICs. For instance, the Global Action Plan for the Prevention and Control of Noncommunicable Diseases 2013-2020 highlights the use of digital health strategies for health education, promotion, and communication, especially in populations with low literacy and health awareness [13]. Examples of using digital health for cervical cancer control include the World Health Organization and the International Telecommunications Union's Be he@lthy, Be mobile initiative, which launched a mobile phone text messaging campaign to improve the awareness of cervical cancer screening in Zambia [14]. In another instance, the Ministry of Health in Peru successfully completed a national pilot program of using text messages to notify women about their HPV screening results [15]. In light of the expanding local, national, and global efforts, evidence of successful implementation and impact is needed to drive further research on and development of digital strategies for cervical cancer control in LMICs.

Currently, much of the published literature describing the use of digital strategies for cervical cancer control comes from high-income settings [16-19]. However, a previous systematic review examined the effectiveness of digital strategies for cervical cancer control in LMICs [20]. In this review, authors identified 8 eligible studies, most of which lacked rigorous study designs and evidence. With the increasing use of digital health strategies in LMICs, an updated review is necessary to evaluate the contextual effectiveness of such strategies for cervical cancer control as compared with high-income settings. Furthermore, the synthesis of key implementation challenges and opportunities for future research is needed to prioritize and increase the success of digital health strategies for cervical cancer control in LMICs.

\section{Objectives}

The primary objectives of the review were to assess the effects of using mobile devices on the following:

- Facilitate task shifting for cervical cancer screening, treatment of precancerous lesions, and management of LMICs as compared with usual care.

- Reduce delays in postscreening treatment initiation among women in LMICs as compared with usual care.

- Assess and improve cervical cancer knowledge or awareness among women in LMICs as compared with usual care.

The secondary objectives were to describe the following:

- Digital health strategies used for cervical cancer control, including those used to visualize the cervix using a mobile device at the point of care in LMICs.

- Challenges associated with the implementation of digital health strategies for cervical cancer control in LMICs.

\section{Methods}

\section{Protocol and Registration}

The review protocol was registered with the PROSPERO database for prospectively registered systematic reviews (protocol \#CRD42017071560). Deviations from the registered protocol and unused methods are included in Multimedia Appendix 1. The findings of this systematic review are reported 
in accordance with the PRISMA (Preferred Reporting Items for Systematic Reviews and Meta-Analyses) checklist and are specified in Multimedia Appendix 2 [21].

\section{Eligibility Criteria}

\section{Participants}

For the assessment of the primary and secondary review objectives, we included studies of all cadres of health care workers (eg, medical doctors, nurses, midwives, community health workers) providing any cervical cancer screening, treatment, and management services, as well as women (of all ages) receiving any cervical cancer education, screening, treatment, and management services.

\section{Interventions}

For the assessment of primary and secondary review objectives, we included any intervention wherein mobile devices were used in the screening, treatment, and management of cervical cancer. These included studies in which mobile devices were used to do the following:

- Facilitate the visualization of the cervix (cervicography).

- Facilitate communication between health care providers for diagnosis, consultation, or referral.

- Provide training or support to health care providers, especially in the context of task shifting.

- Communicate with patients to provide appointment reminders, test results, disease progression monitoring, coordinate services, etc.

- Improve cervical cancer knowledge or awareness among women.

- Facilitate cervical cancer screening, treatment of preinvasive lesions or cervical cancer management.

We excluded the following types of studies:

- Where the intervention used a nonmobile phone device (eg, digital camera, television) to visualize the cervix.

- Where the intervention exclusively focused on the use of mobile devices for providing education about HPV vaccination or to improve its coverage, because these activities generally fall within the purview of immunization programs. In addition, other published systematic reviews have examined the efficacy of mobile phone interventions for HPV vaccination [22-24].

- Where the intervention was only described or conceptualized without actual implementation or evaluation.

- Where abstracts were only published in languages other than English and for which published English translations were not available.

- Where full texts were not available.

- Where the publications were reviews, systematic reviews, conference proceedings, blogs, reports, or other nonpeer-reviewed sources.

\section{Comparators}

Details of the comparator group were extracted from the studies and included in the analysis of primary and secondary review objectives. The comparison was usual care, which could include the use of traditional colposcopy and nondigital, paper-based strategies for data collection, communication, and dissemination in cervical cancer control programs.

\section{Outcomes}

For the review of the primary review objectives, the outcomes of interest were as follows:

1. Coverage and timeliness of cervical cancer screening, treatment, and management.

2. Cervical cancer knowledge or competency (ie, training) of health worker.

3. Cervical cancer knowledge or awareness among women.

Outcome data were not reviewed quantitatively because of the descriptive nature of the secondary review objectives.

\section{Study Design}

We included randomized and nonrandomized controlled study designs (controlled before-and-after studies with at least 2 intervention sites or interrupted time-series studies) in the qualitative synthesis and meta-analysis of the primary review objectives. We included all study designs for a narrative review of the secondary review objectives.

\section{Settings}

For both the primary and secondary review objectives, we included studies from any country listed as low or middle income according to the World Bank Group classification [25].

\section{Information Sources}

\section{Electronic Searches}

The following 5 electronic databases were searched for studies published in English: PubMed, Embase, Web of Science, Scopus, and CINAHL. We included studies from January 1, 1992, to September 19, 2020 (date of search), with 1992 being the year the first commercial text message was sent.

\section{Search Strategy}

A systematic search strategy (Multimedia Appendix 3) was developed, including a detailed search string comprising terms from 3 broad categories, namely, digital health, cervical cancer, and LMICs. The search terms were customized for each of the 5 electronic databases. A Google search was conducted with an abbreviated search string, as described in Multimedia Appendix 3 , and the first 100 search results were analyzed.

\section{Study Selection}

Search records were imported into the reference management software and duplicates were removed. The titles and abstracts of the records were screened according to the predefined eligibility criteria. For each record, 2 reviewers discussed and resolved any ambiguities in screening outcomes during abstract and full-text screening. Interrater reliability was assessed by 2 reviewers independently screening a $10 \%$ sample of sources for inclusion based on abstract evaluation. A Cohen $\kappa$ value of 0.6 was predetermined as an acceptable interrater agreement.

\section{Data Collection Process and Items}

We used a structured template, which was adapted based on the template from Cochrane, to extract relevant data from each 
included study [26]. Primary data items extracted using the template included study location, sample size, population, study duration and design, cervical cancer service or procedure, the description of digital health intervention, conclusions, study limitations, and information for assessing the risk of bias. In addition, quantitative outcome data were extracted from the studies included in the review of the primary objectives.

\section{Risk of Bias in Individual Studies}

We assessed the risk of bias for all studies using the Effective Public Health Practice Project's Quality Assessment Tool for Quantitative Studies [27].

\section{Additional Analyses}

We assessed the quality of data reporting for each included study using the mobile health (mHealth) evidence reporting and assessment (mERA) checklist [28]. This 16-item checklist aims to enhance the replicability of mHealth interventions by promoting the complete reporting of content, context of implementation, and technical features in peer-reviewed publications.

\section{Results}

\section{Study Selection}

Figure 1 shows the results of the study selection process. The systematic search yielded 1707 nonduplicate studies. The overall interrater agreement for screening a $10 \%$ sample was $98.8 \%$, which corresponded to a Cohen $\kappa$ value of 0.76 [29]. Following the abstract screening, 125 records were evaluated using their full text and 95 of those were excluded. Records were excluded after full-text review mainly because they did not describe a peer-reviewed study or because the intervention was conducted in a non-LMIC setting. In total, 30 records corresponding to 27 unique studies [30-59] were included in the final review.

Figure 1. PRISMA (Preferred Reporting Items for Systematic Reviews and Meta-Analyses) flowchart of systematic search results. LMIC: low- and middle-income country; mHealth: mobile health.

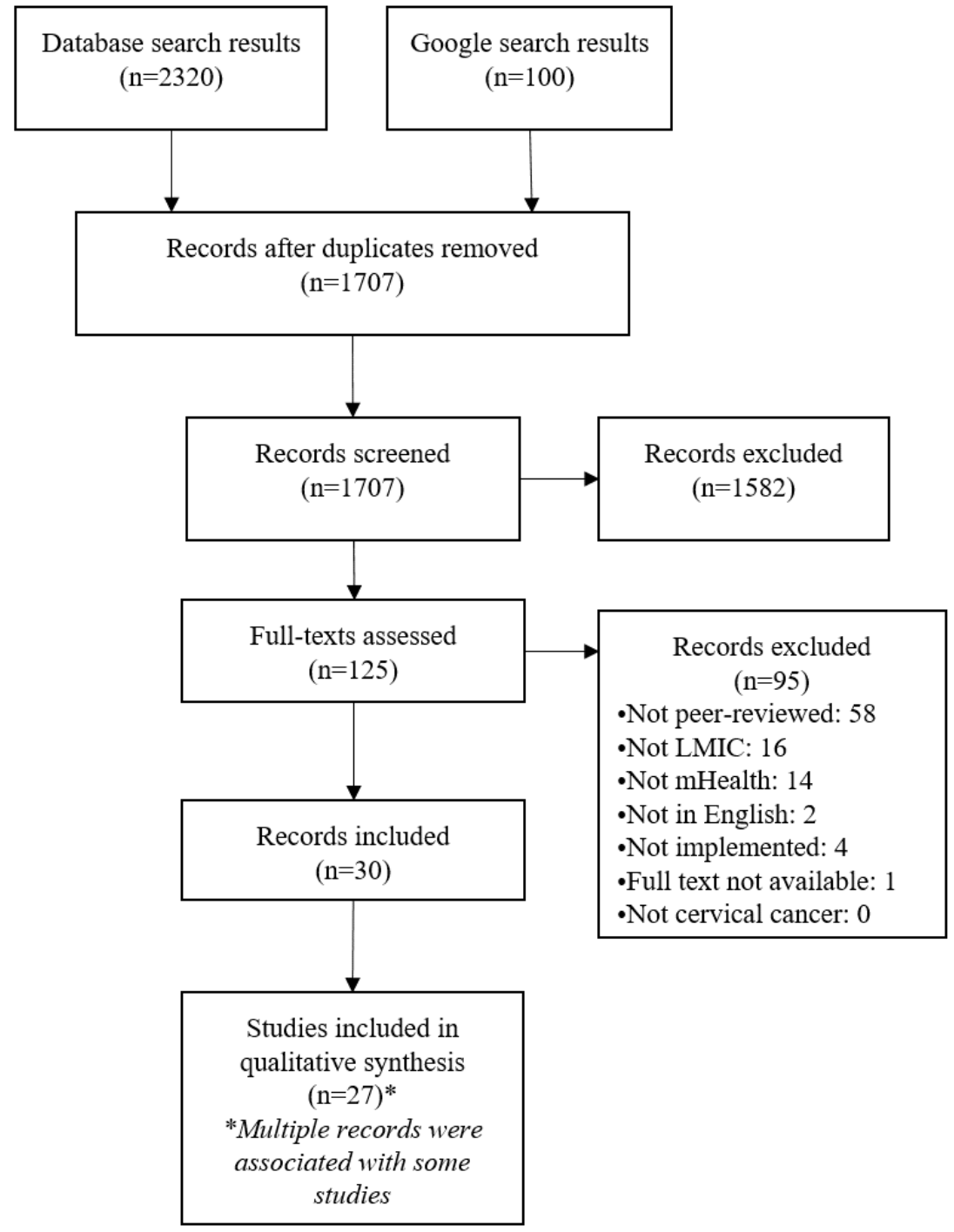

\section{Study Characteristics}

Characteristics of included studies are summarized in Multimedia Appendix 4 [30-59].

\section{Study Design}

In total, 4 included studies were randomized controlled trials (RCTs) [38,40,47-49,59]. These studies met the criteria for inclusion in the review of the primary objectives, that is, the 
effect of digital health strategies on cervical cancer control. A fifth study by Lima et al [41] used random allocation but was excluded from the review of the primary objectives because of the lack of a control group. Huchko et al [39] reported findings of a mixed methods analysis from a cluster RCT; however, the assignment of the digital health strategy was not randomized; thus, it did not meet the criteria for inclusion in the review of primary objectives. All 27 studies were included in the review of the secondary objectives, that is, to describe the digital health strategies used for cervical cancer control in LMICs and the challenges associated with their implementation. Nonrandomized studies used quasi-experimental [32-34,41], cross-sectional [30,31,35-37,46,50,51,53,56,57], or other [52,54,55] study designs. In total, 4 studies [42-45] described program implementation.

\section{Participants}

The studies included 23,393 women and 152 health care workers. Types of health care workers included clinicians (eg, gynecologists, colposcopists, and assistant medical officers), facility-based nurses, and community health nurses.

\section{Intervention}

Many interventions targeted health workers and implemented the use of mobile phones for digital cervicography (ie, imaging of the cervix) or for digital patient data collection [30-32,35-37,42-46,50,51,53-57]. Interventions targeting women were focused on building knowledge or awareness about cervical cancer, delivering reminders to promote the uptake of cervical cancer services or for the notification of test results [33,34,38-41,47-49,52,58,59].

\section{Comparators}

Most of the included studies lacked a parallel control group. Apart from the 4 RCTs and the cluster randomized trial, the only other studies with a control group were Caster et al and Romli et al [34,58].

\section{Outcomes}

Studies using digital cervicography primarily reported diagnostic reliability outcomes such as interrater agreement and sensitivity or specificity as compared with a gold standard diagnostic test such as histology [30,31,35,46,50,51,53-57]. Among the 4 RCTs included in the review of primary objectives, 1 study [40] measured improvement in patient knowledge and all 4 $[38,40,47-49,59]$ measured the uptake of cervical cancer services postintervention. One RCT study [49] included a cost-effectiveness analysis. For the secondary review objectives, all 27 studies included a description of the digital health strategy used and implementation challenges.

\section{Settings}

The review focused on LMICs: 19 studies were conducted in sub-Saharan Africa [30,31,34-39,42-46,50,52,54-56,59], 7 in Asia [32,33,40,47-49,51,53,58], and 1 in South America [41].

\section{Risk of Bias Within Studies}

The analysis results of the risk of bias within the studies are presented in Table 1 (Effective Public Health Practice Project Quality Assessment tool for quantitative studies). Most of the studies $(21 / 27,78 \%)$ were assessed to have a high risk of bias. A total of 2 studies (Erwin et al [38] and Romli et al [58]) were assessed to have a low risk of bias, whereas 4 other studies $[34,40,53,59]$ were assessed to have a moderate risk of bias. 
Table 1. Risk of bias assessment for included studies using the Effective Public Health Practice Project's quality assessment tool for quantitative studies ${ }^{\mathrm{a}}$.

\begin{tabular}{|c|c|c|c|c|c|c|c|}
\hline Study & $\begin{array}{l}\text { Selection } \\
\text { bias }\end{array}$ & $\begin{array}{l}\text { Study } \\
\text { design }\end{array}$ & Confounders & Blinding & $\begin{array}{l}\text { Data collection } \\
\text { method }\end{array}$ & $\begin{array}{l}\text { Withdrawals and } \\
\text { dropouts }\end{array}$ & Global rating \\
\hline $\begin{array}{l}\text { Asgary et al (2016) [30]; Asgary et al } \\
\text { (2019) [31] }\end{array}$ & 1 & 3 & 3 & 2 & 1 & 1 & 3 \\
\hline Bhatt et al (2018) [32] & 3 & 3 & 3 & 3 & 3 & 3 & 3 \\
\hline Caster et al (2015) [34] & 1 & 2 & 3 & 2 & 2 & 1 & 2 \\
\hline Catarino et al (2015) [35] & 2 & 3 & 3 & 2 & 1 & $\mathrm{~N} / \mathrm{A}^{\mathrm{b}, \mathrm{c}}$ & 3 \\
\hline Devi et al (2018) [33] & 3 & 3 & 3 & 3 & 2 & 3 & 3 \\
\hline Erwin et al (2019) [38] & 1 & 1 & 2 & 2 & 2 & 1 & 1 \\
\hline Gallay et al (2017) [36] & 2 & 3 & 1 & 2 & 3 & 1 & 3 \\
\hline Huchko et al (2019) [39] & 1 & 3 & 2 & 3 & 2 & 2 & 3 \\
\hline Khademolhosseini et al (2017) [40] & 2 & 1 & 1 & 3 & 1 & 1 & 2 \\
\hline Lima et al (2017) [41] & 2 & 1 & 1 & 1 & 3 & 3 & 3 \\
\hline Linde et al (2020) [59] & 1 & 1 & 1 & 2 & 3 & 1 & 2 \\
\hline Littman-Quinn et al (2013) [42] & 2 & 3 & 3 & 3 & 3 & 3 & 3 \\
\hline Ndlovu et al (2014) [43] & 2 & 3 & 3 & 3 & 1 & 3 & 3 \\
\hline Parham et al (2010) [44] & 2 & 3 & 3 & 3 & 3 & 3 & 3 \\
\hline Peterson et al (2016) [45] & 1 & 3 & 1 & 3 & 3 & N/A & 3 \\
\hline Quercia et al (2018) [37] & 2 & 3 & N/A & 3 & 1 & 1 & 3 \\
\hline Quinley et al (2011) [46] & 1 & 3 & 3 & 2 & 1 & N/A & 3 \\
\hline $\begin{array}{l}\text { Rashid et al (2013) [47]; Rashid and } \\
\text { Dahlui (2013) [48]; Rashid et al (2014) } \\
\text { [49] }\end{array}$ & 1 & 1 & 3 & 2 & 3 & N/A & 3 \\
\hline Ricard-Gauthier et al (2015) [50] & 2 & 3 & 3 & 2 & 1 & 2 & 3 \\
\hline Romli et al (2020) [58] & 1 & 1 & 1 & 2 & 1 & 1 & 1 \\
\hline Sharma et al (2018) [51] & 2 & 3 & N/A & 3 & 2 & 2 & 3 \\
\hline Swanson et al (2018) [52] & 1 & 2 & 1 & 3 & 3 & 3 & 3 \\
\hline Taghavi et al (2018) [53] & 1 & 3 & N/A & 2 & 1 & 1 & 2 \\
\hline Tran et al (2018) [54] & 2 & 3 & 3 & 2 & 3 & 3 & 3 \\
\hline Urner et al (2017) [55] & 2 & 3 & 1 & 2 & 2 & 3 & 3 \\
\hline Yeates et al (2016) [56] & 2 & 3 & 3 & 3 & 3 & 3 & 3 \\
\hline Yeates et al (2020) [57] & 2 & 3 & 3 & 2 & 3 & 2 & 3 \\
\hline
\end{tabular}

${ }^{\mathrm{a}}$ Scores of 1, 2, and 3 indicate low, moderate, and high risks of bias, respectively. The risk of bias was assessed cumulatively for studies with multiple sources, for example, Asgary et al [30,31].

${ }^{\mathrm{N}} \mathrm{N} / \mathrm{A}$ : not applicable.

${ }^{\mathrm{c}}$ Criteria were not applicable based on a skip pattern in the Effective Public Health Practice Project tool.

\section{Results of Individual Studies}

The study outcomes included in the review of the primary objectives are presented in Table 2. 
Table 2. Outcomes of randomized controlled trial studies included in the review of primary objectives.

\begin{tabular}{|c|c|c|}
\hline Study and participants & Outcome & Result \\
\hline \multicolumn{3}{|c|}{ Erwin et al (2019) [38], N=851 women } \\
\hline $\begin{array}{l}\text { - } 281 \text { controls } \\
\text { - } 272 \text { SMS messaging } \\
\text { - } 298 \text { SMS messaging+e- } \\
\text { voucher }\end{array}$ & $\begin{array}{l}\text { Cervical cancer screening attendance } \\
\text { within } 60 \text { days of randomization (com- } \\
\text { bined for women from rural and urban } \\
\text { settings) }\end{array}$ & $\begin{array}{l}\text { Women in the SMS messaging group had } \\
\text { 3.0 higher adjusted odds of attendance as } \\
\text { compared with women in the control group } \\
\text { Women in the SMS messaging+e-voucher } \\
\text { group had } 4.7 \text { higher adjusted odds of atten- } \\
\text { dance as compared with women in the } \\
\text { control group } \\
\text { Women in the SMS messaging+e-voucher } \\
\text { group had } 1.5 \text { times higher adjusted odds } \\
\text { of attendance compared with women in the } \\
\text { SMS messaging group }\end{array}$ \\
\hline
\end{tabular}

\section{Khademolhosseini et al (2017) [40], $\mathrm{N}=95$ women}

- 47 control

- 48 intervention

- 47 control

- 48 intervention
Mean difference in pre- and posttraining knowledge among women in the intervention group as compared with those in the control group measured immediately and 3 months after SMS messaging-based training
Uptake of Pap test within 3 months of training in the intervention group compared with control group
- Women in the intervention group had a mean increase in the knowledge of 8.18 points from baseline as compared with a mean increase of 0.27 points from baseline in the control group immediately posttraining

- Women in the intervention group had a mean increase in the knowledge of 8.35 points from baseline as compared with a mean increase of 0.17 points in the control group at 3 months of posttraining

- $\quad$ At 3 months of posttraining, only 4 (5.8\%) participants of the control group as compared with $23(47.9 \%)$ participants of the intervention group had received a Pap test
Summary of

risk of bias ${ }^{\mathrm{a}}$

The overall risk of bias was assessed to be low

The overall risk of bias was assessed to be moderate

The overall risk of bias was assessed to be moderate

Linde et al (2020) [59], $\mathrm{N}=705$ women

- $\quad 347$ standard of care (control)

- 358 standard of care+text message
The attendance rate of follow-up cervical cancer screening among $\mathrm{HPV}^{\mathrm{b}}$-positive women
Compared with standard of care, a written appointment card, the addition of one-way text messages had no effect on follow-up cervical cancer screening among HPVpositive women
The overall risk of bias was assessed to be moderate

\section{Rashid and Dahlui (2013) [48], N=1000 women}

- 250 letters

- 250 registered letters

- 250 SMS messaging

- 250 phone calls

- 250 letters

- 250 registered letters

- 250 SMS messaging

- 250 phone calls
The uptake of Pap test in response to recall through phone call as compared with recall by letter

The uptake of Pap test in response to recall through SMS messaging as compared with recall by letter
Compared with women receiving recall by letter, those receiving recall by phone call had 2.38 times higher odds of receiving a Pap smear of bias was assessed to be high

The overall risk of bias was assessed to be high

\footnotetext{
${ }^{\mathrm{b}} \mathrm{HPV}$ : human papillomavirus.

\section{Synthesis of Results}

Findings From the Review of Primary Objectives: Effectiveness of Digital Health Strategies for Cervical Cancer Control
}

${ }^{\mathrm{a}}$ Assessed using the Effective Public Health Practice Project risk of bias assessment tool for quantitative studies.

We did not conduct a meta-analysis of the included studies because of variations in the nature of the interventions, outcome measures, and small number of studies included in the primary review of the effect of mobile devices. The only included study with a low risk of bias found that SMS behavior change communication messaging in conjunction with transportation e-voucher led to an increased uptake of cervical cancer screening (Table 2) [38]. 


\section{Findings From the Review of Secondary Objectives:} Description of Strategies Used

We adapted a published mHealth framework for noncommunicable diseases to facilitate the narrative synthesis of the digital health strategies used in the included studies [4,60]. Framework adaptation allowed for the mapping of included studies to various stages of the cervical cancer control cascade (primary prevention, secondary prevention, treatment, and palliation) as well as the key individual, provider, and health system challenges (knowledge, access, quality, and continuity of care) addressed by the included studies. The mapping results are presented in Table 3. Only the digital health components of the study interventions were mapped and any nondigital components (community sensitization, paper educational booklets administered before digital reminders, etc) were excluded. Many studies addressed multiple challenges; hence, digital health strategies were mapped to all the applicable challenges in the framework.

Table 3. Landscape of digital health strategies for cervical cancer prevention and control.

\begin{tabular}{|c|c|c|c|c|c|}
\hline \multirow{3}{*}{$\begin{array}{l}\text { Individual-, provider- and health system-level } \\
\text { challenges in cervical cancer control }\end{array}$} & \multicolumn{5}{|c|}{ Stages in cervical cancer prevention and control } \\
\hline & \multirow{2}{*}{$\begin{array}{l}\text { Primary prevention } \\
\text { HPV }^{\mathrm{a}} \text { vaccination }\end{array}$} & \multicolumn{2}{|l|}{ Secondary prevention } & \multicolumn{2}{|c|}{$\begin{array}{l}\text { Treatment and palliative } \\
\text { care }\end{array}$} \\
\hline & & Screening (study) & $\begin{array}{l}\text { Treatment of precancer- } \\
\text { ous lesions (study) }\end{array}$ & Treatment & $\begin{array}{l}\text { Palliative } \\
\text { care }\end{array}$ \\
\hline \multicolumn{6}{|l|}{ Knowledge and awareness } \\
\hline Low knowledge of HPV or cervical cancer & $\begin{array}{l}\text { Not within the scope } \\
\text { of this review }\end{array}$ & $5[34,38,40,58,59]$ & $1[34]$ & 0 & 0 \\
\hline $\begin{array}{l}\text { Low knowledge of cervical cancer screening } \\
\text { or treatment services }\end{array}$ & $\begin{array}{l}\text { Not within the scope } \\
\text { of this review }\end{array}$ & $\begin{array}{l}6 \\
{[34,38,40,41,58,59]^{\mathrm{b}}}\end{array}$ & $1[34]$ & 0 & 0 \\
\hline \multicolumn{6}{|l|}{ Access to care } \\
\hline $\begin{array}{l}\text { Low access to health facilities or cervical } \\
\text { cancer services }\end{array}$ & $\begin{array}{l}\text { Not within the scope } \\
\text { of this review }\end{array}$ & $1[38]$ & 0 & 0 & 0 \\
\hline $\begin{array}{l}\text { Low availability of appropriate and accurate } \\
\text { screening or treatment methods }\end{array}$ & $\begin{array}{l}\text { Not within the scope } \\
\text { of this review }\end{array}$ & $\begin{array}{l}15 \\
{[30,31,35,36,42-46,} \\
50,51,53-57]^{\mathrm{c}}\end{array}$ & 0 & 0 & N/A \\
\hline Low access to experts & $\begin{array}{l}\text { Not within the scope } \\
\text { of this review }\end{array}$ & $\begin{array}{l}15 \\
{[30,31,35,36,42-46,} \\
50,51,53-57]\end{array}$ & 0 & 0 & 0 \\
\hline Financial barriers & $\begin{array}{l}\text { Not within the scope } \\
\text { of this review }\end{array}$ & $1[38]$ & 0 & 0 & 0 \\
\hline \multicolumn{6}{|l|}{ Continuity of care } \\
\hline A low uptake of follow-up services & $\begin{array}{l}\text { Not within the scope } \\
\text { of this review }\end{array}$ & $\begin{array}{l}7[33,39,41,47-49 \\
52,58,59]\end{array}$ & 0 & 0 & N/A \\
\hline \multicolumn{6}{|l|}{ Quality of care } \\
\hline $\begin{array}{l}\text { A lack of training opportunities for health } \\
\text { workers }\end{array}$ & $\begin{array}{l}\text { Not within the scope } \\
\text { of this review }\end{array}$ & $\begin{array}{l}10 \\
{[30,31,35,36,42-44} \\
46,51,56,57]^{\mathrm{c}}\end{array}$ & 0 & 0 & 0 \\
\hline Poor data availability & $\begin{array}{l}\text { Not within the scope } \\
\text { of this review }\end{array}$ & $\begin{array}{l}19[30-32,35-37,39 \\
42-46,50-57]\end{array}$ & $2[32,45]$ & 0 & 0 \\
\hline
\end{tabular}

\footnotetext{
${ }^{\mathrm{a}} \mathrm{HPV}$ : human papillomavirus.

${ }^{\mathrm{b}}$ Represents the number of included studies mapped to each category. For example, we found 3 studies that aimed to increase the demand for screening by increasing women's knowledge of human papillomavirus or cervical cancer.

${ }^{\mathrm{c}}$ Some studies were associated with multiple records, for example, Asgary et al [30,31].
}

A majority of the included studies used digital health strategies for secondary prevention; only Caster et al [34] focused on educating women about treatment, whereas Bhatt et al [32] and Peterson et al [45] collected data related to postscreening treatment. None of the included studies focused on cervical cancer treatment or palliative care. Studies related to primary prevention (HPV vaccination) were not within the scope of the study. Although most included studies focused on increasing screening or treatment among all eligible women, some studies focused on high-risk populations, and in particular, HPV-positive women [35-37,50,53,54,59].

1. Knowledge and awareness: in total, 6 studies mapped to this domain and included digital health strategies to educate women about HPV, cervical cancer, and cervical cancer 
prevention or treatment services. These studies $[34,38,40,41,58,59]$ focused primarily on increasing the screening uptake: Khademolhosseini et al [40] used an educational intervention delivered via an instant messaging platform called Telegram. They used a diverse range of content including text messages, posters, infographics, podcasts, and video tutorials. Lima et al [41] tested a telephone intervention focused on increasing the patient's knowledge of cervical cancer and Pap smears. In the study by Erwin et al [38], women in one study arm received 15 behavior change communication messages via SMS messages that were designed to increase their knowledge and awareness about cervical cancer screening. Caster et al [34] implemented a tablet-based cervical cancer education program to facilitate patient education about screening. Opportunities for interaction with the educational content were through quizzes, or while navigating the content on the tablet. Caster et al [34] also included educational content related to treatment and was the only study to do so.

2. Access to care: only one study, by Erwin et al [38], used digital health to reduce transportation and financial barriers to health care access. Women randomized to one of the study arms received e-vouchers through their mobile phone, which covered the costs of a return trip to the health facility. In total, 15 studies used smartphones for facilitating digital cervicography and visualizing the cervix during VIA at the point of care [30,31,35,36,42-46,50,51,53-57]. In total, 7 studies included visual inspection with Lugol iodine images in addition to VIA images [35-37,50,53-55]. Although most studies used the mobile phone camera for image acquisition, Peterson et al [45] and Taghavi et al [53] used smartphone attachments for enhanced cervix visualization. These studies allowed for task shifting, as mobile devices were used to acquire cervical images, record diagnosis, and receive or compare diagnoses with remote experts. Images and relevant patient data were shared with the experts via a text/multimedia message service or by uploading data to a web-based database. Parham et al [44] used an automated text messaging system to reduce the time between screening, diagnosis, and treatment by sending a text message requesting expert review of an image while the patient was still in the clinic. Yeates et al [56,57] used WhatsApp to send patient images, nurse diagnosis, and treatment plans for expert review and subsequently developed the SEVIA app to accomplish these tasks.

3. Continuity of care: in total, 7 studies tested digital strategies for reminding or recalling patients for follow-up services $[33,39,41,47-49,52,58,59]$. These studies focused on women who had already received some cervical cancer services. All 7 studies tested SMS-based reminders or recall messages. In total, 3 studies [39,47-49,52] also tested phone calls. Other nondigital modalities included letters, registered letters, home visits, and return visits to the clinic.

4. Quality of care: studies mapped to this domain focused on 2 key applications: training health workers and improving data availability. In most cases, the training covered the acquisition of good-quality images using cervicography and expert feedback to improve the accuracy of diagnosis $[30,31,35,36,42-44,46,51,56,57]$. In Botswana, Littman-Quinn et al [42] provided additional ongoing medical education content to health workers via tablet devices to complement in-service training. Studies using digital cervicography were also mapped to this domain as the documentation of cervical images during VIA can improve data availability for patient management, and hence, improve the quality of care. Two studies, Bhatt et al [32] and Peterson et al [45], collected treatment information in addition to information about screening results. In the study by Bhatt et al [32], a SIM-based app was loaded on feature phones provided to trained nurses. The nurses used a menu-based protocol on the feature phone for entering data.

\section{Findings From the Review of Secondary Objectives: Implementation Challenges}

In the included studies, the authors described several technical challenges in implementing digital health strategies for cervical cancer control in LMICs. These challenges were based on lessons learned and, in a few cases [31,32], on formal qualitative data collected during the study. In addition to the technical challenges, many studies described inadequacies in the underlying health system resources (eg, availability of pelvic exam rooms and lack of supplies for cryotherapy in community health centers [30]), which impacted study implementation. Digital health strategies were not implemented in a vacuum; several studies described the need for increasing the community knowledge and awareness of cervical cancer as well as reducing stigma and fear related to cancer screening/diagnosis in parallel with the implementation of digital health strategies $[30,32,37,38,41,44,45,51]$. One study also described negative attitudes toward cervical cancer screening among health care workers as an issue [51]. Some authors emphasized the need for strong partnerships and stakeholder support for the success and future sustainability of digital health strategies $[42,43,45,51]$. Table 4 shows the technical challenges in implementing digital health strategies for cervical cancer control. 
Table 4. Description of implementation challenges for digital health strategies for cervical cancer control.

\begin{tabular}{|c|c|c|}
\hline $\begin{array}{l}\text { Implementation } \\
\text { challenge }\end{array}$ & Included studies & Description and examples \\
\hline $\begin{array}{l}\text { High training require- } \\
\text { ments }\end{array}$ & {$[30,31,34,35,43,44,51,54]$} & $\begin{array}{l}\text { - Pretraining lasting several weeks, providing supplemental training for augmenting skills, } \\
\text { refresher training to minimize loss of skills, and the availability of experts to provide ongoing } \\
\text { feedback for using digital cervicography } \\
\text { - Catarino et al [35]: } 5 \text { weeks of training on digital cervicography to medical students } \\
\text { - Asgary et al [30,31]: additional one-on-one training to community health nurses in } \\
\text { cases where the digital image quality was low } \\
\text { - Ndlovu et al [43]: high training requirements on the touchscreen features } \\
\text { - Caster et al [34]: Users had limited previous experience with technology (but needed } \\
\text { very little support for using the tablet device). }\end{array}$ \\
\hline
\end{tabular}

Technology-specific $\quad[30,32,36,42-44,46,50,54,55] \quad$ - Procurement of appropriate technology

challenges

- Challenges with the availability of technology options in the study area in preparation for and during the study [30,32]

- Considerations related to finding mobile phone cameras with high image quality and zoom capabilities [30,43,46,54,55]

- The use of high-pixel smartphone cameras were associated with better reported quality of images [50]; however, Tran et al [54] suggested that the quality was inferior to colposcopy images.

- Parham et al [44]: need to send cameras out of the country for repairs was a challenge

- Software and hardware issues: software "bugs," crashing of apps, device malfunctions, and an insufficient battery life [36,42-44]

- Gallay et al [36]: loss of patient data due to the unexpected crash of their data collection app

- Data security issues

- Littman-Quinn et al [42]: security breach (attack by an anonymous hacker) lead researchers to increase data security to the level of compliance described in the Health Insurance Portability and Accountability Act

- Software updates

- $\quad$ Bhatt et al [32]: challenges in updating a SIM-based app requiring project staff to collect all SIM cards to update the app

- Littman-Quinn et al [42]: challenges with communication when the technical team was based in a different country and did not speak the same language as the end users, reflecting the need for local technology development capacity for the sustainability of digital health strategies

Infrastructure chal- $\quad[31,32,42,43,45,46]$ lenges

Challenges with technology reach

$[39,47-49]$

Inequitable access to $[38,39,52]$ technology
- Issues with network coverage and electrical outages as limitations to widespread implementation

- Bhatt et al [32]: challenges faced by nurses from hillier communities in sending patient data and receiving acknowledgment of report submission

- Yeates et al [56]: health care workers given solar-powered chargers and light sources for anticipated power outages and to allow use of digital cervicography in off-site settings

\section{Additional Analysis: Quality of Digital Health Reporting}

The quality of reporting scores according to the mERA checklist is summarized in Multimedia Appendix 5 [30-59]. The mERA scores ranged from 1 to 10 , out of a maximum possible score
- $\quad$ Rashid et al [47-49]: letters were more likely to be successfully and reliably delivered to patients than phone text messages or calls because of connectivity and coverage issues (incorrect phone numbers and nonresponse)

- Rashid et al [47-49] and Huchko et al [39]: direct communication through phone call encouraged more women to seek screening (both studies had a high risk of bias, limiting our confidence in their findings)

- Exclusion of women without mobile phones from digital health intervention components in some studies of 16. The mERA checklist items frequently described in the studies included the technology platform and details of intervention delivery. Poorly described items were related to digital health infrastructure necessary for implementation, interoperability with other existing digital health systems, usability testing during development, and intervention 
replicability, with 6 or fewer included studies describing these characteristics.

\section{Discussion}

\section{Summary of Evidence}

Our review findings show that the majority of the studies in LMICs used digital health strategies to facilitate the screening and treatment of precancerous lesions (ie, secondary prevention) as compared with the treatment of invasive cancer or palliative care. Even though our search attempted to include any relevant studies since 1992, the date of the earliest included study was 2010. Within the realm of secondary prevention, strategies focused on improving women's knowledge and awareness about cervical cancer, increasing access to cervical cancer services, improving the training of health workers and availability of data, and ensuring the continuity of care. Key challenges in implementing digital health strategies for cervical cancer control were related to the high burden of training, technology-specific issues, infrastructure challenges, challenges with technology reach, and inequitable access to technology among target users. We were unable to determine the quantitative effect of digital health strategies on cervical cancer control because of the small numbers and inadequate quality of studies for meta-analysis. Only one randomized controlled study identified in this review with a low risk of bias found that SMS behavior change communication messaging in conjunction with a transportation e-voucher leads to an increased uptake of cervical cancer screening. Most of the studies included in the review had a high risk of bias and were rated poorly in terms of the quality of reporting of the digital health strategy.

\section{Implications for Research and Practice}

This review identified several gaps in the literature. These gaps are summarized below, along with their implications for research and practice:

1. Improve the evidence base for the effectiveness of digital health strategies for cervical cancer control: there is insufficient evidence related to the effectiveness of digital health strategies for cervical cancer screening and treatment. The included studies implemented digital health strategies mostly for secondary prevention, and there are opportunities to investigate the use of digital health for cervical cancer treatment and palliative care. Other bottlenecks in the cervical cancer control cascade that may benefit from using digital health include improving access to health facilities (eg, through the use of digital telemedicine), reducing financial barriers (eg, provision of phone vouchers), and supporting disease management among women diagnosed with invasive cancer (eg, using digital knowledge interventions).

2. Use more rigorous study designs: among the 27 included studies, only 4 studies used an RCT design [38,40,47-49,59] and only one of these studies had a low risk of bias [38]. The high or moderate risk of bias among the remaining studies limited our confidence in their findings. Future studies should consider using rigorous study designs that minimize the risk of bias.

3. Improve the reporting of digital health strategies in the literature: in our review, only 5 studies [35-37,39,54,57,59] met the mERA checklist item on replicability, indicating that many of the digital health strategies identified in this review would be difficult to replicate and re-evaluate based on published information. The use of reporting checklists ensures that all relevant information is presented to readers to assist with study reproducibility.

4. Expand research on LMIC settings in Asia and South America: a majority (70\%) of the included studies took place in sub-Saharan Africa, indicating an opportunity to expand research to other LMIC settings with a high burden of cervical cancer.

\section{Limitations}

Our synthesis of the literature is limited by the availability of peer-reviewed reports of digital health strategies for cervical cancer control. We tried to mitigate this limitation by using a systematic search strategy and searching 5 large databases and Google to identify relevant studies. We did not search any trial databases for ongoing studies or to examine other gray literature sources. Hence, we may have missed ongoing implementations and emerging data on using digital health for cervical cancer control.

\section{Conclusions}

There is insufficient evidence to determine the effectiveness of digital health strategies for cervical cancer control in LMICs. The only RCT study identified in this review with a low risk of bias found that SMS behavior change communication messaging in conjunction with a transportation e-voucher led to an increased uptake of cervical cancer screening. Future efforts are needed to investigate the use of digital health strategies across the cervical cancer control continuum and in LMIC settings outside of sub-Saharan Africa.

\section{Acknowledgments}

The authors would like to thank Patricia G Moorman, PhD, for providing feedback on the early drafts of the manuscript and Christina Makarushka, MPH, for coordinating this review. This study was funded by a pilot grant from the Duke Cancer Initiative and 1R01CA195500 Quick Trials: a viable solution for a see and treat paradigm for cervical precancer in Africa, and 1R01CA19338001 AIP: Culturally Appropriate Screening and Diagnosis of Cervical Cancer in East Africa to NR. HWR and LV receive funding from the National Center for Advancing Translational Sciences of the National Institutes of Health under award numbers TL1TR002555 and KL2TR002554, respectively. The content is solely the responsibility of the authors and does not necessarily represent the official views of the National Institutes of Health. 


\section{Authors' Contributions}

LV conceived the study and protocol. AHR, LV, and MVI developed the search terms. The medical librarian (MVI) conducted the systematic search. AHR, LV, CM, and HWR screened studies for inclusion, and AHR, LV, MMP, CM, and HWR extracted data and completed the bias analysis. AHR developed figures and tables. AHR and LV cowrote the first draft of the manuscript. All authors have revised the manuscript and approved the final version for submission.

\section{Conflicts of Interest}

One review author $(\mathrm{MJH})$ was listed as an author on 2 included studies and did not participate in the risk of bias assessment of any included study. The authors declare no other conflicts of interest.

\section{Multimedia Appendix 1}

Protocol deviations and unused methods.

[DOCX File, 14 KB-Multimedia Appendix 1]

\section{Multimedia Appendix 2}

PRISMA (Preferred Reporting Items for Systematic Reviews and Meta-Analyses) checklist. [DOCX File, 19 KB-Multimedia Appendix 2]

\section{Multimedia Appendix 3}

Systematic search strategy, customized by database.

[DOCX File, 26 KB-Multimedia Appendix 3]

\section{Multimedia Appendix 4}

Characteristics of included studies.

[DOCX File, 28 KB-Multimedia Appendix 4]

\section{Multimedia Appendix 5}

Quality of reporting of including studies using the mHealth evidence reporting and assessment (mERA) checklist.

[DOCX File, 22 KB-Multimedia Appendix 5]

\section{References}

1. Human papillomavirus (HPV) and cervical cancer. World Health Organization. 2020 Nov 11. URL: https://www.who.int/ news-room/fact-sheets/detail/human-papillomavirus-(hpv)-and-cervical-cancer [accessed 2020-06-16]

2. Catarino R, Petignat P, Dongui G, Vassilakos P. Cervical cancer screening in developing countries at a crossroad: emerging technologies and policy choices. World J Clin Oncol 2015 Dec 10;6(6):281-290 [FREE Full text] [doi:

10.5306/wjco.v6.i6.281] [Medline: 26677441]

3. Demment MM, Peters K, Dykens JA, Dozier A, Nawaz H, McIntosh S, et al. Developing the evidence base to inform best practice: a scoping study of breast and cervical cancer reviews in low- and middle-income countries. PLoS One 2015 Sep 1;10(9):e0134618 [FREE Full text] [doi: 10.1371/journal.pone.0134618] [Medline: 26325181]

4. Labrique AB, Vasudevan L, Kochi E, Fabricant R, Mehl G. mHealth innovations as health system strengthening tools: 12 common applications and a visual framework. Glob Health Sci Pract 2013 Aug 06;1(2):160-171. [doi:

10.9745/ghsp-d-13-00031]

5. Mehl G, Labrique A. Prioritizing integrated mHealth strategies for universal health coverage. Sci 2014 Sep 12;345(6202):1284-1287. [doi: 10.1126/science.1258926] [Medline: 25214614]

6. Jit M, Brisson M, Portnoy A, Hutubessy R. Cost-effectiveness of female human papillomavirus vaccination in 179 countries: a PRIME modelling study. Lancet Glob Health 2014 Jul;2(7):406-414. [doi: 10.1016/s2214-109x(14)70237-2]

7. Gelband H, Sankaranarayanan R, Gauvreau CL, Horton S, Anderson BO, Bray F, et al. Costs, affordability, and feasibility of an essential package of cancer control interventions in low-income and middle-income countries: key messages from Disease Control Priorities, 3rd edition. Lancet 2016 May;387(10033):2133-2144. [doi: 10.1016/s0140-6736(15)00755-2]

8. Maranga IO, Hampson L, Oliver AW, Gamal A, Gichangi P, Opiyo A, et al. Analysis of factors contributing to the low survival of cervical cancer patients undergoing radiotherapy in Kenya. PLoS One 2013 Oct 30;8(10):e78411 [FREE Full text] [doi: 10.1371/journal.pone.0078411] [Medline: 24205226]

9. Gakidou E, Nordhagen S, Obermeyer Z. Coverage of cervical cancer screening in 57 countries: low average levels and large inequalities. PLoS Med 2008 Jun 17;5(6):e132 [FREE Full text] [doi: 10.1371/journal.pmed.0050132] [Medline: 18563963] 
10. World Health Organization. Who Guidelines for Screening and Treatment of Precancerous Lesions for Cervical Cancer Prevention. Geneva: World Health Organization; 2013:1-58.

11. Comprehensive Cervical Cancer Control: A Guide to Essential Practice. Second Edition. World Health Organization. 2014. URL: http://apps.who.int/iris/bitstream/handle/10665/144785/9789241548953_eng.pdf [accessed 2021-04-29]

12. Sankaranarayanan R, Budukh AM, Rajkumar R. Effective screening programmes for cervical cancer in low- and middle-income developing countries. Bull World Health Organ 2001;79(10):954-962 [FREE Full text] [Medline: 11693978]

13. World Health Organization. Global action plan for the prevention and control of NCDs 2013-2020. In: Noncommunicable Diseases and Mental Health. Geneva: World Health Organization; 2013:1-55.

14. WHO, ITU. Be He@ @lthy, Be Mobile Annual Report 2016. In: Noncommunicable Diseases and Their Risk Factors. Geneva: World Health Organization; 2016.

15. Gidman W, Coomber R. Contested space in the pharmacy: public attitudes to pharmacy harm reduction services in the West of Scotland. Res Social Adm Pharm 2014 May;10(3):576-587. [doi: 10.1016/j.sapharm.2013.07.006] [Medline: 24021859]

16. Im H, Castro CM, Shao H, Liong M, Song J, Pathania D, et al. Digital diffraction analysis enables low-cost molecular diagnostics on a smartphone. Proc Natl Acad Sci U S A 2015 May 05;112(18):5613-5618 [FREE Full text] [doi: 10.1073/pnas.1501815112] [Medline: 25870273]

17. Lee HY, Koopmeiners JS, Rhee TG, Raveis VH, Ahluwalia JS. Mobile phone text messaging intervention for cervical cancer screening: changes in knowledge and behavior pre-post intervention. J Med Internet Res 2014 Aug 27;16(8):e196 [FREE Full text] [doi: 10.2196/jmir.3576] [Medline: 25164545]

18. Sahin D, Hacisalihoglu UP, Kirimlioglu SH. Telecytology: is it possible with smartphone images? Diagn Cytopathol 2018 Jan 08;46(1):40-46. [doi: 10.1002/dc.23851] [Medline: 29115040]

19. Tanaka Y, Ueda Y, Okazawa A, Kakuda M, Matsuzaki S, Kobayashi E, et al. 'Smartscopy' as an alternative device for cervical cancer screening: a pilot study. BMJ Innov 2017 Apr 30;3(2):123-126 [FREE Full text] [doi:

10.1136/bmjinnov-2016-000174] [Medline: 28794895]

20. DiCarlo J, Gopakumar S, Dhillon P, Krishnan S. Adoption of information and communication technologies for early detection of breast and cervical cancers in low- and middle-income countries. J Glob Oncol 2016 Aug;2(4):222-234 [FREE Full text] [doi: 10.1200/JGO.2015.002063] [Medline: 28717705]

21. Moher D, Liberati A, Tetzlaff J, Altman DG, PRISMA Group. Preferred reporting items for systematic reviews and meta-analyses: the PRISMA statement. PLoS Med 2009 Jul 21;6(7):e1000097 [FREE Full text] [doi:

10.1371/journal.pmed.1000097] [Medline: 19621072]

22. Badawy SM, Kuhns LM. Texting and mobile phone app interventions for improving adherence to preventive behavior in adolescents: a systematic review. JMIR Mhealth Uhealth 2017 Apr 19;5(4):e50 [FREE Full text] [doi: 10.2196/mhealth.6837] [Medline: 28428157]

23. Francis DB, Cates JR, Wagner KP, Zola T, Fitter JE, Coyne-Beasley T. Communication technologies to improve HPV vaccination initiation and completion: a systematic review. Patient Educ Couns 2017 Jul;100(7):1280-1286. [doi: 10.1016/j.pec.2017.02.004] [Medline: 28209248]

24. Smulian EA, Mitchell KR, Stokley S. Interventions to increase HPV vaccination coverage: a systematic review. Hum Vaccin Immunother 2016 Jun 02;12(6):1566-1588 [FREE Full text] [doi: 10.1080/21645515.2015.1125055] [Medline: $\underline{26838959]}$

25. World bank country and lending groups. World Bank Group. 2018. URL: https://datahelpdesk.worldbank.org/knowledgebase/ articles/906519-world-bank-country-and-lending-groups [accessed 2021-03-12]

26. Noyes JH, Booth A, Harris J, Harden A, Popay J, Pearson A, Noyes. Chapter 5: Extracting qualitative evidence. Cochrane Qualitative \& Implementation Methods Group. 2010. URL: http://cqrmg.cochrane.org/supplemental-handbook-guidance [accessed 2021-03-12]

27. Quality assessment tool for quantitative studies. Effective Public Health Practice Project. 2010. URL: https://link.springer.com/ content/pdf/bbm\%3A978-3-319-17284-2\%2F1.pdf [accessed 2021-03-12]

28. Agarwal S, LeFevre AE, Lee J, L'Engle K, Mehl G, Sinha C, WHO mHealth Technical Evidence Review Group. Guidelines for reporting of health interventions using mobile phones: mobile health (mHealth) evidence reporting and assessment (mERA) checklist. Br Med J 2016 Mar 17;352:i1174. [doi: 10.1136/bmj.i1174] [Medline: 26988021]

29. Torgerson C. Systematic Reviews. London, United Kingdom: A\&C Black; 2003:1-102.

30. Asgary R, Adongo PB, Nwameme A, Cole HV, Maya E, Liu M, et al. mHealth to train community health nurses in visual inspection with acetic acid for cervical cancer screening in Ghana. J Low Genit Tract Dis 2016;20(3):239-242. [doi: 10.1097/lgt.0000000000000207]

31. Asgary R, Cole H, Adongo P, Nwameme A, Maya E, Adu-Amankwah A, et al. Acceptability and implementation challenges of smartphone-based training of community health nurses for visual inspection with acetic acid in Ghana: mHealth and cervical cancer screening. BMJ Open 2019 Jul 16;9(7):e030528 [FREE Full text] [doi: 10.1136/bmjopen-2019-030528] [Medline: $\underline{31315879}$ ]

32. Bhatt S, Isaac R, Finkel M, Evans J, Grant L, Paul B, et al. Mobile technology and cancer screening: lessons from rural India. J Glob Health 2018 Dec;8(2):020421 [ㅌREE Full text] [doi: 10.7189/jogh.08.020421] [Medline: 30603075] 
33. Devi S, Dasila P, Suryavanshi MR. Effect of educational intervention followed by reminders regarding participation of women in the cervical screening programme. Ind J Pub Health Res \& Develop 2018;9(9):369. [doi: 10.5958/0976-5506.2018.01026.4]

34. Caster MM, Norris AH, Butao C, Reese PC, Chemey E, Phuka J, et al. Assessing the acceptability, feasibility, and effectiveness of a tablet-based cervical cancer educational intervention. J Cancer Educ 2017 Mar 5;32(1):35-42 [FREE Full text] [doi: 10.1007/s13187-015-0953-6] [Medline: 26637473]

35. Catarino R, Vassilakos P, Scaringella S, Undurraga-Malinverno M, Meyer-Hamme U, Ricard-Gauthier D, et al. Smartphone use for cervical cancer screening in low-resource countries: a pilot study conducted in Madagascar. PLoS One 2015 Jul 29;10(7):e0134309 [FREE Full text] [doi: 10.1371/journal.pone.0134309] [Medline: 26222772]

36. Gallay C, Girardet A, Viviano M, Catarino R, Benski A, Tran PL, et al. Cervical cancer screening in low-resource settings: a smartphone image application as an alternative to colposcopy. Int J Women's Health 2017 Jun; Volume 9:455-461. [doi: 10.2147/ijwh.s136351]

37. Quercia K, Tran PL, Jinoro J, Herniainasolo JL, Viviano M, Vassilakos P, et al. A mobile health data collection system for remote areas to monitor women participating in a cervical cancer screening campaign. Telemed J E Health 2018 Apr;24(4):277-282. [doi: 10.1089/tmj.2017.0146] [Medline: 28846504]

38. Erwin E, Aronson KJ, Day A, Ginsburg O, Macheku G, Feksi A, et al. SMS behaviour change communication and eVoucher interventions to increase uptake of cervical cancer screening in the Kilimanjaro and Arusha regions of Tanzania: a randomised, double-blind, controlled trial of effectiveness. BMJ Innov 2019 Jan 22;5(1):28-34 [FREE Full text] [doi: 10.1136/bmjinnov-2018-000276] [Medline: 31645991]

39. Huchko MJ, Saduma I, Blat C, Oketch S, Bukusi EA. How providing cervical cancer screening results via cell phone affects patient follow-up rates in Western Kenya. J Glob Oncol 2019 Dec(5):1-8. [doi: 10.1200/jgo.18.00264]

40. Khademolhosseini F, Noroozi A, Tahmasebi R. The effect of health belief model-based education through Telegram instant messaging services on pap smear performance. Asian Pac J Cancer Prev 2017 Aug 27;18(8):2221-2226 [FREE Full text] [doi: 10.22034/APJCP.2017.18.8.2221] [Medline: 28843259]

41. Lima TM, Nicolau AI, Carvalho FH, Vasconcelos CT, Aquino PD, Pinheiro AK. Telephone interventions for adherence to colpocytological examination. Rev Lat Am Enfermagem 2017 Feb 06;25:e2844 [FREE Full text] [doi: 10.1590/1518-8345.1683.2844] [Medline: 28177055]

42. Littman-Quinn R, Mibenge C, Antwi C, Chandra A, Kovarik CL. Implementation of m-health applications in Botswana: telemedicine and education on mobile devices in a low resource setting. J Telemed Telecare 2013 Feb 01;19(2):120-125. [doi: 10.1177/1357633x12474746] [Medline: 23454821]

43. Ndlovu K, Littman-Quinn R, Park E, Dikai Z, Kovarik CL. Scaling up a mobile telemedicine solution in Botswana: keys to sustainability. Front Public Health 2014 Dec 11;2:275 [FREE Full text] [doi: 10.3389/fpubh.2014.00275] [Medline: 25566520]

44. Parham GP, Mwanahamuntu M, Pfaendler K, Sahasrabuddhe VV, Myung D, Mkumba G, et al. eC3--a modern telecommunications matrix for cervical cancer prevention in Zambia. J Low Genit Tract Dis 2010 Jul;14(3):167-173 [FREE Full text] [doi: 10.1097/LGT.0b013e3181cd6d5e] [Medline: 20592550]

45. Peterson CW, Rose D, Mink J, Levitz D. Real-time monitoring and evaluation of a visual-based cervical cancer screening program using a decision support job aid. Diagnostics (Basel) 2016 May 16;6(2):20 [FREE Full text] [doi: 10.3390/diagnostics6020020] [Medline: 27196932]

46. Quinley KE, Gormley RH, Ratcliffe SJ, Shih T, Szep Z, Steiner A, et al. Use of mobile telemedicine for cervical cancer screening. J Telemed Telecare 2011 May 06;17(4):203-209 [FREE Full text] [doi: 10.1258/jtt.2011.101008] [Medline: 21551217]

47. Rashid RM, Mohamed M, Hamid ZA, Dahlui M. Is the phone call the most effective method for recall in cervical cancer screening?--results from a randomised control trial. Asian Pac J Cancer Prev 2013 Oct 30;14(10):5901-5904 [FREE Full text] [doi: 10.7314/apjcp.2013.14.10.5901] [Medline: 24289597]

48. Rashid RM, Dahlui M. Study protocol for the most effective recall method in a cervical cancer screening program in Klang, Malaysia. Asian Pac J Cancer Prev 2013 Oct 30;14(10):5867-5870 [FREE Full text] [doi: 10.7314/apjcp.2013.14.10.5867] [Medline: 24289591]

49. Rashid RM, Ramli S, John J, Dahlui M. Cost effective analysis of recall methods for cervical cancer screening in Selangor--results from a prospective randomized controlled trial. Asian Pac J Cancer Prev 2014 Jul 15;15(13):5143-5147 [FREE Full text] [doi: 10.7314/apjcp.2014.15.13.5143] [Medline: 25040965]

50. Ricard-Gauthier D, Wisniak A, Catarino R, van Rossum AF, Meyer-Hamme U, Negulescu R, et al. Use of smartphones as adjuvant tools for cervical cancer screening in low-resource settings. J Low Genit Tract Dis 2015 Oct;19(4):295-300. [doi: 10.1097/LGT.0000000000000136] [Medline: 26247260]

51. Sharma D, Rohilla L, Bagga R, Srinivasan R, Jindal HA, Sharma N, et al. Feasibility of implementing cervical cancer screening program using smartphone imaging as a training aid for nurses in rural India. Public Health Nurs 2018 Nov 28;35(6):526-533. [doi: 10.1111/phn.12517] [Medline: 29806745] 
52. Swanson M, Ibrahim S, Blat C, Oketch S, Olwanda E, Maloba M, et al. Evaluating a community-based cervical cancer screening strategy in Western Kenya: a descriptive study. BMC Womens Health 2018 Jul 03;18(1):116 [FREE Full text] [doi: 10.1186/s12905-018-0586-0] [Medline: 29970063]

53. Taghavi K, Banerjee D, Mandal R, Kallner HK, Thorsell M, Friis T, et al. Colposcopy telemedicine: live versus static swede score and accuracy in detecting CIN2+, a cross-sectional pilot study. BMC Womens Health 2018 Jun 11;18(1):89 [FREE Full text] [doi: 10.1186/s12905-018-0569-1] [Medline: 29890991]

54. Tran PL, Benski C, Viviano M, Petignat P, Combescure C, Jinoro J, et al. Performance of smartphone-based digital images for cervical cancer screening in a low-resource context. Int J Technol Assess Health Care 2018 Jan;34(3):337-342. [doi: 10.1017/S0266462318000260] [Medline: 29921339]

55. Urner E, Delavy M, Catarino R, Viviano M, Meyer-Hamme U, Benski A, et al. A smartphone-based approach for triage of human papillomavirus-positive sub-saharan african women: a prospective study. JMIR Mhealth Uhealth 2017 May 29;5(5):e72 [FREE Full text] [doi: 10.2196/mhealth.6697] [Medline: 28554879]

56. Yeates KE, Sleeth J, Hopman W, Ginsburg O, Heus K, Andrews L, et al. Evaluation of a smartphone-based training strategy among health care workers screening for cervical cancer in Northern Tanzania: the Kilimanjaro method. J Glob Oncol 2016 Dec;2(6):356-364. [doi: 10.1200/jgo.2015.001768]

57. Yeates K, Erwin E, Mtema Z, Magoti F, Nkumbugwa S, Yuma S, et al. Smartphone-enhanced training, qa, monitoring, and evaluation of a platform for secondary prevention of cervical cancer: opportunities and challenges to implementation in Tanzania. JCO Glob Oncol 2020 Nov(6):1114-1123. [doi: 10.1200/go.20.00124]

58. Romli R, Shahabudin S, Saddki N, Mokhtar N. Effectiveness of a health education program to improve knowledge and attitude towards cervical cancer and pap smear: a controlled community trial in Malaysia. Asian Pac J Cancer Prev 2020 Mar 01;21(3):853-859. [doi: 10.31557/apjcp.2020.21.3.853]

59. Linde DS, Andersen MS, Mwaiselage J, Manongi R, Kjaer SK, Rasch V. Effectiveness of one-way text messaging on attendance to follow-up cervical cancer screening among human papillomavirus-positive Tanzanian women (connected2care): parallel-group randomized controlled trial. J Med Internet Res 2020 Apr 02;22(4):e15863 [FREE Full text] [doi: 10.2196/15863] [Medline: 32238335]

60. Bloomfield GS, Vedanthan R, Vasudevan L, Kithei A, Were M, Velazquez EJ. Mobile health for non-communicable diseases in Sub-Saharan Africa: a systematic review of the literature and strategic framework for research. Global Health 2014 Jun 13;10(1):49 [FREE Full text] [doi: 10.1186/1744-8603-10-49] [Medline: 24927745]

\author{
Abbreviations \\ HPV: human papillomavirus \\ LMIC: low- and middle-income country \\ mERA: mobile health evidence reporting and assessment \\ mHealth: mobile health \\ PRISMA: Preferred Reporting Items for Systematic Reviews and Meta-Analyses \\ RCT: randomized controlled trial \\ VIA: visual inspection with acetic acid
}

Edited by G Eysenbach; submitted 17.08.20; peer-reviewed by K Morley, W Evans; comments to author $11.09 .20 ;$ revised version
received 01.01.21; accepted 13.01.21; published 27.05.21
Please cite as:
Rossman AH, Reid HW, Pieters MM, Mizelle C, von Isenburg M, Ramanujam N, Huchko MJ, Vasudevan L
Digital Health Strategies for Cervical Cancer Control in Low- and Middle-Income Countries: Systematic Review of Current
Implementations and Gaps in Research
J Med Internet Res 2021;23(5):e23350
URL: $\underline{\text { https://www.jmir.org/2021/5/e23350 }}$
doi: $\underline{10.2196 / 23350}$
PMID:

(C)Andrea H Rossman, Hadley W Reid, Michelle M Pieters, Cecelia Mizelle, Megan von Isenburg, Nimmi Ramanujam, Megan J Huchko, Lavanya Vasudevan. Originally published in the Journal of Medical Internet Research (https://www.jmir.org), 27.05.2021. This is an open-access article distributed under the terms of the Creative Commons Attribution License (https://creativecommons.org/licenses/by/4.0/), which permits unrestricted use, distribution, and reproduction in any medium, provided the original work, first published in the Journal of Medical Internet Research, is properly cited. The complete bibliographic 
information, a link to the original publication on https://www.jmir.org/, as well as this copyright and license information must be included. 